\title{
The smoothing effect for renewable resources in an Afro-Eurasian power grid
}

\author{
Maria Krutova $^{1,2}$, Alexander Kies ${ }^{1,3}$, Bruno U. Schyska ${ }^{1}$, and Lueder von Bremen ${ }^{1}$ \\ ${ }^{1}$ ForWind, Center for Wind Energy Research, University of Oldenburg, Oldenburg, Germany \\ ${ }^{2}$ Wind Energy Department, Technical University of Denmark, Lyngby, Denmark \\ ${ }^{3}$ Frankfurt Institute for Advanced Studies, Goethe University Frankfurt, Frankfurt, Germany \\ Correspondence to: Maria Krutova (maria.krutova@uni-oldenburg.de)
}

Received: 15 January 2017 - Revised: 13 June 2017 - Accepted: 15 June 2017 - Published: 27 July 2017

\begin{abstract}
Renewable power systems have to cope with highly variable generation. Increasing the spatial extent of an interconnected power transmission grid smooths the feed-in by exchange of excess energy over long distances and therefore supports renewable power integration. In this work, we investigate and quantify the balancing potential of a supergrid covering Europe, Africa and Asia. We use ten years of historical weather data to model the interplay of renewable generation and consumption and show that a pan-continental Afro-Eurasian supergrid can smooth renewable generation to a large extent and reduce the need for backup energy by around $50 \%$. In addition, we show that results for different weather years vary by up to approximately $50 \%$.
\end{abstract}

\section{Introduction}

The growing shares of feed-in from renewable sources of wind and photovoltaics (PV) pose a demanding challenge to stable operation of power systems (Lund, 2008; Kies et al., 2016a). Generation from renewable sources is not dispatchable, but highly fluctuating and therefore cannot replace dispatchable generation from conventional sources directly. Instead, power systems, which rely on renewable generation sources, need additional balancing means. Possibilities include backup, storage (Weitemeyer et al., 2016; Pleßmann, 2014; Heide et al., 2011) or reinforced transmission grid (Brown, 2014).

Alternatives aim to increase the usage of system-friendly renewables (Hirth et al., 2016; Chattopadhyay et al., 2017), which describe, for instance, the deployment of renewable generation facilities with respect to being part of a highly renewable power system instead of focusing on meteorological conditions alone. An example is to optimize the mix of renewables (Santos-Alamillos et al., 2012; Tafarte et al., 2014; Kies et al., 2016c; Heide et al., 2010; Lund, 2006; VidalAmaro et al., 2015; Francois et al., 2016; Jurasz and Ciapała, 2017). Besides taking measures on the generation side, it is possible to modify the consumption side via demand side management (which usually refers to load shifting; Strbac, 2008; Kies et al., 2016d or sector coupling Brown et al., 2017).

In the final consequence, increasing the spatial extent of a power grid leads to a pan-continental or even global supergrid. A vision of such global grid was put forward by (Chatzivasileiadis et al., 2013, 2014). Furthermore, Chinese president Xi Jinping proposed discussions on a "global energy internet" in a keynote speech at the UN Sustainable Development Summit ${ }^{1}$ in September 2015. The concept was also discussed in more detail by the State Grid Corporation of China (Wang, 2015). The needs for infrastructure of a global supergrid were recently discussed by (Dahl et al., 2017).

In this paper, we investigate the potential benefit from the smoothing effect for renewable feed-in in a pan-continental supergrid connecting large parts of Europe, Asia and Africa. For this purpose, we quantify the benefit as a reduction in the need for backup energy in a highly renewable power system where renewable generation equals demand on average. In addition, we quantify the year-to-year variability of the need for backup energy. First, we determine the optimal mix of wind and photovoltaics generation for every node in the network independently (Sect. 3). Using these optimal mixes, we

\footnotetext{
${ }^{1}$ www.sgcc.com.cn/ywlm/mediacenter/corporatenews/
} 


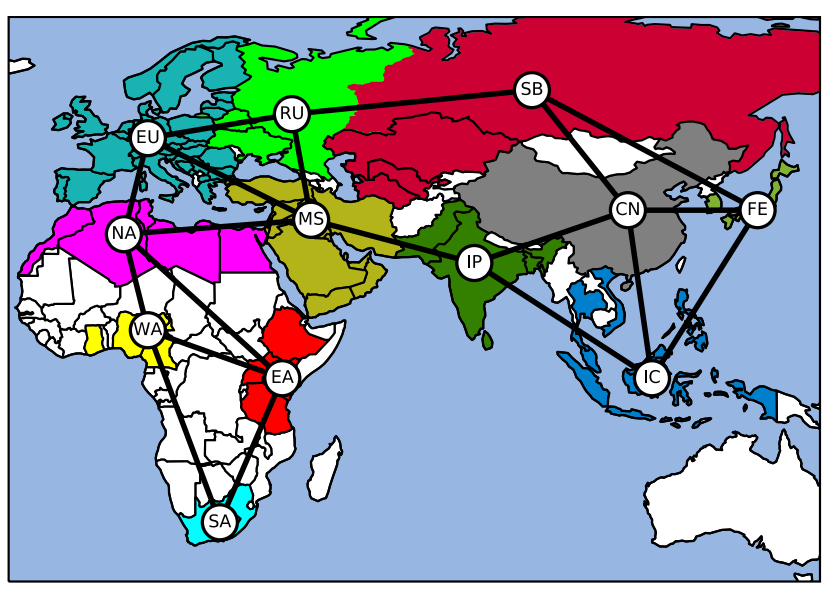

Figure 1. The investigated simplified power system consists of super regions connected by long distance transmission lines.

investigate the potential reduction of the need for backup in the grid connecting three continents in Sect. 4. In Sect. 5 we investigate the smoothing effect further by iteratively connecting nodes to the grid starting with Europe processing eastwards.

\section{Methodology}

We simulate a simplified power network covering large parts of Eurasia and Africa. Super regions within this network are represented as nodes (Fig. 1), which are connected by longdistance transmission lines.

Each node produces energy from the renewable sources of wind and photovoltaics (PV). The time series of renewable production of node $n$ is given by $G_{n}(t)=G_{n}^{W}(t)+G_{n}^{S}(t)$, where $G_{n}^{W}$ and $G_{n}^{S}$ refer to the partial generation time series from wind and PV, respectively. In addition, each node has a load time series $L_{n}(t)$. The mismatch between generation from renewable sources and load, $\Delta_{n}(t)=G_{n}(t)-L_{n}(t)$ needs to be balanced by the system, i.e.,

$\Delta_{n}(t)=C_{n}(t)-B_{n}(t)+P_{n}(t)$.

$C_{n}(t)$ is curtailment time series, $B_{n}(t)$ is backup generation from perfectly flexible power plants and $P_{n}(t)$ is the injection pattern (exports - imports), which describes the usage of the transmission grid. Backup time series are calculated via

$B_{n}(t)=-\min \left\{0, \Delta_{n}(t)-P_{n}(t)\right\}$

We are interested in two major quantities concerning the need for backup:

1. the need for backup energy $B_{n}^{E}$ of a node, defined via

$$
B_{n}^{E}=\int B_{n}(t) \mathrm{d} t
$$

Table 1. Considered regions and their average load.

\begin{tabular}{llr}
\hline Region & Countries & $\langle L\rangle[\mathrm{GW}]$ \\
\hline EU & EU countries & 572 \\
NA & Algeria, Egypt, Libya, Morocco, Tunisia & 63 \\
WA & Cameroon, Ghana, Nigeria & 19 \\
EA & Ethiopia, Kenya, Tanzania, Uganda & 20 \\
SA & South Africa & 14 \\
RU & European Russia, Belarus, Ukraine & 66 \\
MS & Arabic countries, Israel, Turkey & 159 \\
IP & Bangladesh, India, Pakistan, Sri Lanka & 258 \\
SB & Asian Russia, Kazakhstan, Uzbekistan & 19 \\
IC & Indonesia, Malaysia, Philippines, & 163 \\
& Thailand, Vietnam & 676 \\
CN & China & 226 \\
FE & South Korea, Japan & \\
\hline
\end{tabular}

2. the need for backup capacity $B_{n}^{C}$, i.e., the generation capacity of dispatchable generation that needs to be kept at hand, defined via

$0.99=\int_{0}^{B_{n}^{C}} p\left(B_{n}(t)\right) \mathrm{d} p$,

$p($.$) describes the distribution function of backup$ events. The 99th percentile is chosen to reduce the sensitivity towards the weather database. The same assumption is made for instance by (Dahl et al., 2017).

Transmission bottlenecks within single regions are not considered in these calculations.

\subsection{Generation and load data}

For Europe, we model generation and load data with a temporal resolution of one hour and a spatial resolution of $7 \mathrm{~km}$ covering years 2003-2012. Load data is taken from ENTSO$\mathrm{E}$ and modified according to expected changes due to electrification of transport and heating within the R\&D project RESTORE 2050. Wind speeds are taken from statistically downscaled MERRA reanalysis data (Rienecker et al., 2011). Details on generation data are given by (Kies et al., 2016b, 2015). For all other regions, we use data from MERRA reanalysis without downscaling.

Since real time-resolved load data is only for Europe available to us, the load time series of node $n \neq \mathrm{EU}$ is modelled as

$$
\begin{aligned}
L_{n}(t) & =\left\langle L_{n}\right\rangle\left[1-\frac{1}{4} \cos \left(\frac{\pi t}{4380}\right)\right. \\
& \left.-\frac{1}{4} \sin \left(\frac{\pi(t+\tau+4)}{12}\right)\right]+\varepsilon_{t},
\end{aligned}
$$

where $\tau$ is the GMT time zone offset and $\left\langle L_{n}\right\rangle$ is proportional to the projected GDP by 2050 (Ward, 2012). Table 1 shows 
average load per node,

$\left\langle L_{n}\right\rangle=\left\langle L_{\mathrm{EU}}\right\rangle \frac{\mathrm{GDP}_{n}^{2050}}{\mathrm{GDP}_{\mathrm{EU}}^{2050}}$.

$\varepsilon_{t}$ is a random normally distributed value $\mathcal{N}\left(0,0.04\left\langle L_{n}\right\rangle\right)$ representing short term fluctuations.

Use of projected GDP determines the nodes which we consider in our model. GDP, and therefore load, of the countries not listed is assumed negligible. Russia is split into two parts. However, all of its demand is assumed to be concentrated in the European part (RU), which is more densely populated and industrialized. Asian part of Russia (SB) is considered solely a renewable energy provider.

\subsection{Transmission}

We use power flow equations in a common linear approximation. $F_{l}$ denotes the flow over link $l$ and can be either positive or negative (the sign indicates the direction of the flow). Flows and the injection pattern $P$ are related via

$F=\mathrm{PTDF} \cdot P$

PTDF is the Power Transfer Distribution Factor matrix, which we calculate via

$\mathrm{PTDF}=K^{T} L^{+}$

where $K$ is the incidence matrix and $L^{+}$the Moore-Penrose pseudoinverse of the Laplacian matrix of the network defined as $L=K^{T} K$. The transmission system is operated to minimize the need for backup energy and modelled as a two-step optimization problem. The first step reads

$$
\begin{array}{ll}
\underset{P(t)}{\operatorname{minimize}} & \sum_{n} B_{n}(t)=: B^{\mathrm{min}}(t) \\
\text { subjectto } & \sum_{n} P_{n}(t)=0 \\
& F_{l}^{-}<F_{l}(t) \leq F_{l}^{+} .
\end{array}
$$

However, the solution $F_{l}$ of this optimization problem is usually degenerate. The second step ensures the uniqueness of the solution by minimizing the squared flows. This can be understood as minimizing dissipation losses (which are $\propto F^{2}$ ) and reads

$$
\begin{array}{cl}
\underset{P(t)}{\operatorname{minimize}} & \sum_{l} F_{l}^{2} \\
\text { subjectto } & \sum_{n} P_{n}(t)=0 \\
& F_{l}^{-}<F_{l}(t) \leq F_{l}^{+} \\
& \sum_{n} B_{n}(t)=B^{\min }(t) .
\end{array}
$$

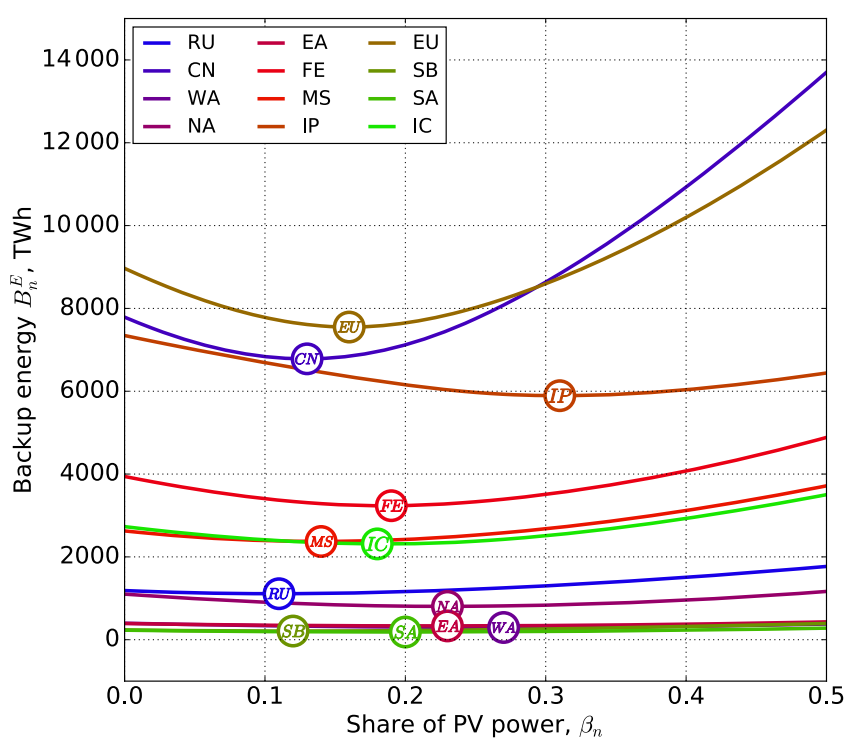

Figure 2. Backup energy need in dependency of the corresponding wind/PV mix. Markers are placed at the position of the optimal power mix.

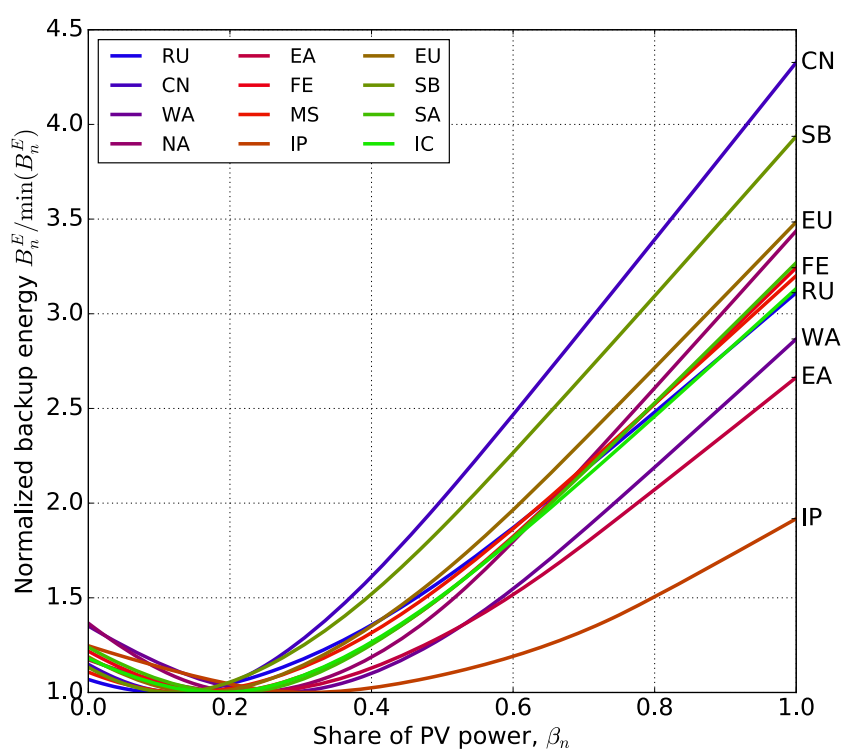

Figure 3. Growth of the backup energy need in dependency of wind/PV mix. Backup energy is normalized to the corresponding minimum values.

Once the time series of flows via a certain link $l$ are known, its required transmission capacity $T_{l}^{C}$ can be computed via

$0.99=\int_{0}^{T_{l}^{C}} p\left(\left|F_{l}(t)\right|\right) \mathrm{d} p$,

An equivalent transmission model is, for instance, used by (Kies et al., 2016d). 
Table 2. Optimal PV share for each autonomous node.

\begin{tabular}{ll|lr|ll}
\hline Region & $\beta_{n}^{\text {opt }}$ & Region & $\beta_{n}^{\text {opt }}$ & Region & $\beta_{n}^{\text {opt }}$ \\
\hline RU & 0.11 & EU & 0.16 & EA & 0.23 \\
SB & 0.12 & IC & 0.18 & NA & 0.23 \\
CN & 0.13 & FE & 0.19 & WA & 0.27 \\
MS & 0.14 & SA & 0.2 & IP & 0.31 \\
\hline
\end{tabular}

\section{Wind/PV mix}

Before we investigate benefits resulting from smoothing in the following sections, we neglect transmission and optimize the mix of wind/PV for every node independently. We define the mix to be optimal, if the resulting need for backup energy is minimized. The corresponding optimization problem for node $n$ reads

$$
\begin{array}{cl}
\underset{\beta_{n}}{\operatorname{minimize}} & B_{n}^{E} \\
\text { subjectto } & 0 \leq \beta_{n} \leq 1 \\
& \alpha_{n}=1 \\
& F_{l}=0 \forall l,
\end{array}
$$

where $\beta_{n}$ is the share of PV power in the renewable generation mix and $\alpha_{n}$ is the renewable penetration at the node $n$.

$\begin{aligned} \beta_{n} & =\frac{\left\langle G_{n}^{S}(t)\right\rangle}{\left\langle G_{n}(t)\right\rangle} \\ \alpha_{n} & =\frac{\left\langle G_{n}(t)\right\rangle}{\left\langle L_{n}(t)\right\rangle} .\end{aligned}$

The need for backup energy in dependency of the renewable mix is shown for all nodes in Fig. 2. The optimal share values are provided in Table 2.

It can be observed that the optimal solar shares for all nodes lie between 0.11 and 0.31 . Similar investigations have shown that in Europe a solar share of ca. 0.4 minimizes monthly standard deviation (Heide et al., 2010).

An obvious outlier is the IP node, containing India. It has the highest value as optimal PV share and also an interesting property of being the node, where the relative need for backup energy is lowest in a PV-dominated scenario (Fig. 3). This seems to be caused by a lower correlation of PV feedin. However, further investigation is required to quantify the reason for this effect. Optimal shares of African nodes are grouped in range $0.2-0.3$ with West Africa node (WA) having the highest $\beta_{n}^{\text {opt }}$ of them.

The total renewable generation of each region in the following sections is calculated with power mixes resulting from optimal $\beta_{n}^{\text {opt }}$.
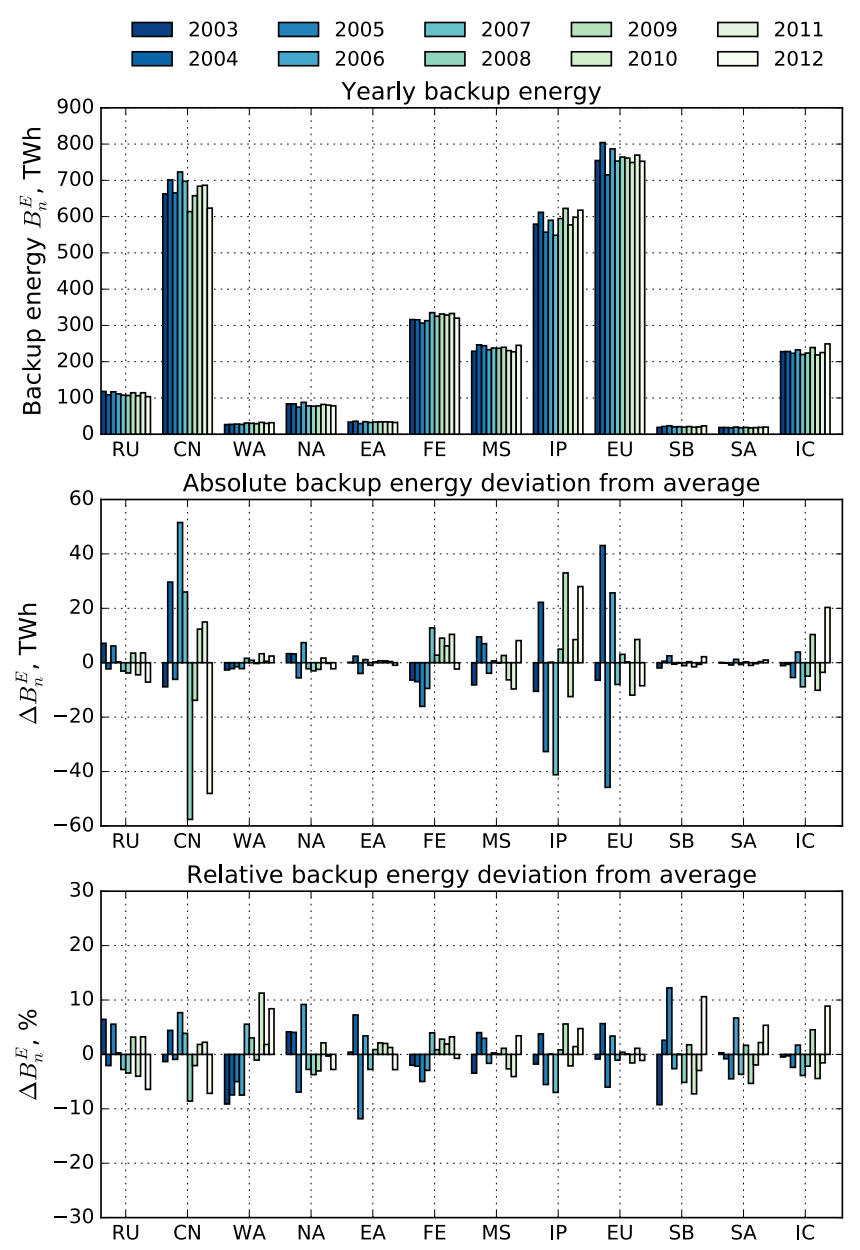

Figure 4. Yearly backup energy need and its deviation from 10-year average $\Delta B_{n}^{C}=\left\langle B_{n}^{C}\right\rangle-B_{n}^{C}$ for the isolated regions with $\alpha=1$.

\section{Afro-Eurasia}

The next step is to investigate the impact of the smoothing effect on the need for backup energy in the supergrid. The yearly variation of the backup energy need of the single regions is shown in Fig. 4 for isolated regions and Fig. 5, if all of them are connected. While yearly patterns of the deviation from average are similar in both cases, relative differences increase in case of the supergrid. The main reason for this is overall decrease of the backup need in the grid, and therefore - the average backup, by around $50 \%$. Absolute deviations stay within the same range as in the case of isolated nodes, while relative deviation increases because of the lower average.

Yet not all nodes see backup deviation change proportional to overall backup reduction. This is the result of linking nodes through the transmission grid. In case of isolated regions the excess renewable power is not shared with other nodes. Therefore, nodes with comparably high demand have to balance it with their local resources. When nodes partici- 

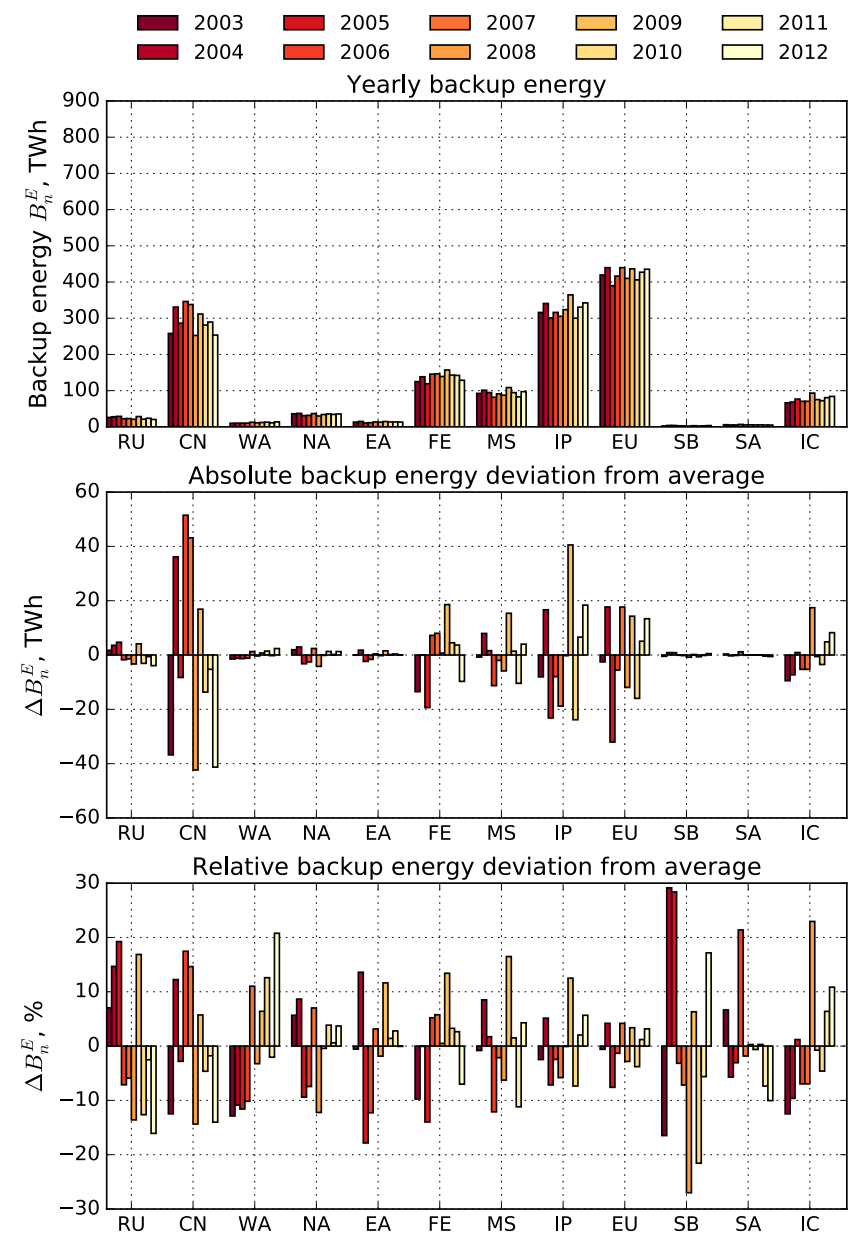

Figure 5. Yearly backup energy need and its deviation from 10-year average $\Delta B_{n}^{C}=\left\langle B_{n}^{C}\right\rangle-B_{n}^{C}$ for Afro-Eurasian grid with $\alpha=1$.

pate in power exchange, excess renewable power is used to balance the demand throughout the grid.

In addition, the reduction for backup energy need is higher, if the year is favourable for wind and solar power generation. Hence, relative yearly differences are additionally emphasized in the grid due to different weather years. For some nodes, backup energy requirements of consecutive years vary by $40-50 \%$. This comparison emphasizes the importance of considering more than a single weather year to obtain reliable results in renewable power system analysis.

The total 10-year need for backup energy in dependency of the renewable penetration $\alpha$ for several transmission grid setups (Table 3) is investigated by linking different groups of Eurasian and African nodes. The global renewable penetration is defined similarly to Eq. (14) through global generation and load averages, where distribution is assumed to be homogeneous, i.e. $\alpha_{n}=\alpha$ for all nodes.

The different setups allow to explore, how the need for backup energy is effected as more regions are connected through the transmission grid. If all Afro-Eurasian nodes are
Table 3. Transmission grid setups. While all regions are always present in the simulation, some of them are not connected to a grid. Node to node links correspond to topology suggested in Fig. 1

\begin{tabular}{lll}
\hline Grid setup ID & Linked regions & Isolated regions \\
\hline 1. Isolated regions & None & All \\
2. EU extended & EU, RU, NA, MS & SB, IP, CN, IC, \\
& & FE, WA, EA, SA \\
3. EU ext. + Africa & EU, RU, NA, MS, & $\begin{array}{l}\text { SB, IP, CN, } \\
\text { IC, FE }\end{array}$ \\
& WA, EA, SA & \\
4. EU ext. + Asia & EU, RU, NA, MS, & WA, EA, SA \\
& SB, IP, CN, IC, FE & \\
5. Eurasia + Africa & All & None \\
\hline
\end{tabular}

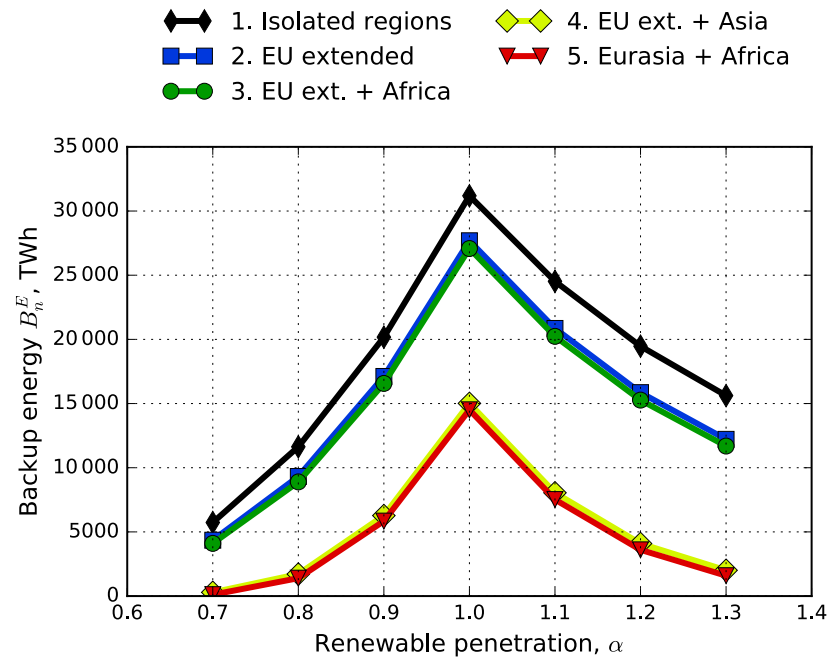

Figure 6. Need for backup energy for different grid toplogies in dependency of the renewable penetration.

connected, a reduction by around $50 \%$ is observed compared to isolated regions for $\alpha=1$ (Fig. 6).

The decrease is mainly caused by the interconnection between Europe and Asia, whereas adding the connection between Europe and Africa has only a small beneficial effect, as seen by comparing setups $2-3$ and $4-5$. The maximum backup reduction is reached when all regions are linked into the intercontinental Afro-Eurasian grid (setup 5). The much smaller benefits from linking Europe and Africa compared to Europe and Asia are, besides the lesser spatial extent, most likely caused by high correlation of solar feed-in in Europe and Africa as they belong to similar longitudes.

\section{Eurasia}

It is shown in the previous section that major benefits stem from the extension of the European power grid to the east, i.e., Asia. Therefore, we investigate this option further and compute a different set of grid configurations. We start 
with isolated regions and then link regions one by one from west to east. The first simulated grid contains only the link between $\mathrm{EU}+\mathrm{RU}$, the second comprises a triangle $\mathrm{EU}+\mathrm{RU}+\mathrm{MS}$, and so on until all Eurasian regions are connected. Figure 7 shows the need for backup energy, backup capacity and transmission capacity in dependency of the grid extension. The transmission capacity is summed up for all links containing a corresponding node.

It can be observed that connecting RU, IP and $\mathrm{CN}$ causes the biggest decrease in the need for backup energy and backup capacity for the European Union (EU). This is likely caused by the fact that they are modelled as having a similar average load and generation due to the projected size of their economies in 2050.

However, extending the transmission network to the east comes at the price of a large need for transmission capacities. Comparing EU + RU to the case of entire Eurasia shows transmission capacities to grow for Europe by a factor of 7 . It is notable, that transmission needs increase for all nodes with the grid extension, except for MS, which sees a small decrease after the node $\mathrm{CN}$ is connected. Possessing a very high demand, the $\mathrm{CN}$ node redirects power flows to itself, thus slightly relieving the power exchange through MS.

\section{Discussion, summary and conclusions}

In this work, we have investigated a pan-continental supergrid. Technologically, such a supergrid would most likely depend on high-voltage direct-current (HVDC) transmission systems. Components of such systems mostly already exist today. However, because converters, cables, and other components for HVDC are more expensive than those for AC as of today, they are economically inefficient for short connections, but HVDC systems become advantageous over long distances because of favourable features, such as easy transfer of power between grids that are operating at different frequencies.

The greatest obstacle for a global supergrid seems to be a fair cost-allocation mechanism. Even on the country level, costs for different system components and their allocation to consumers and generators is the subject of regular dispute. However, the advantages of such global grid, including the ones presented in this paper, can make future research and efforts promoting global cooperation on renewable energy generation and exchange appear meaningful.

A straightforward extension of this work would be to include storage options in the calculations. (Bogdanov et al., 2015) have found for a similar Eurasian grid that HVDC transmission leads to a cut-off of storage utilization and decrease the need for primary generation capacities.

In our calculations it was shown that such a grid has the potential to reduce the need for backup energy by up to one half by transmitting energy surpluses via long distances to cover energy deficits. This is a comparable number as
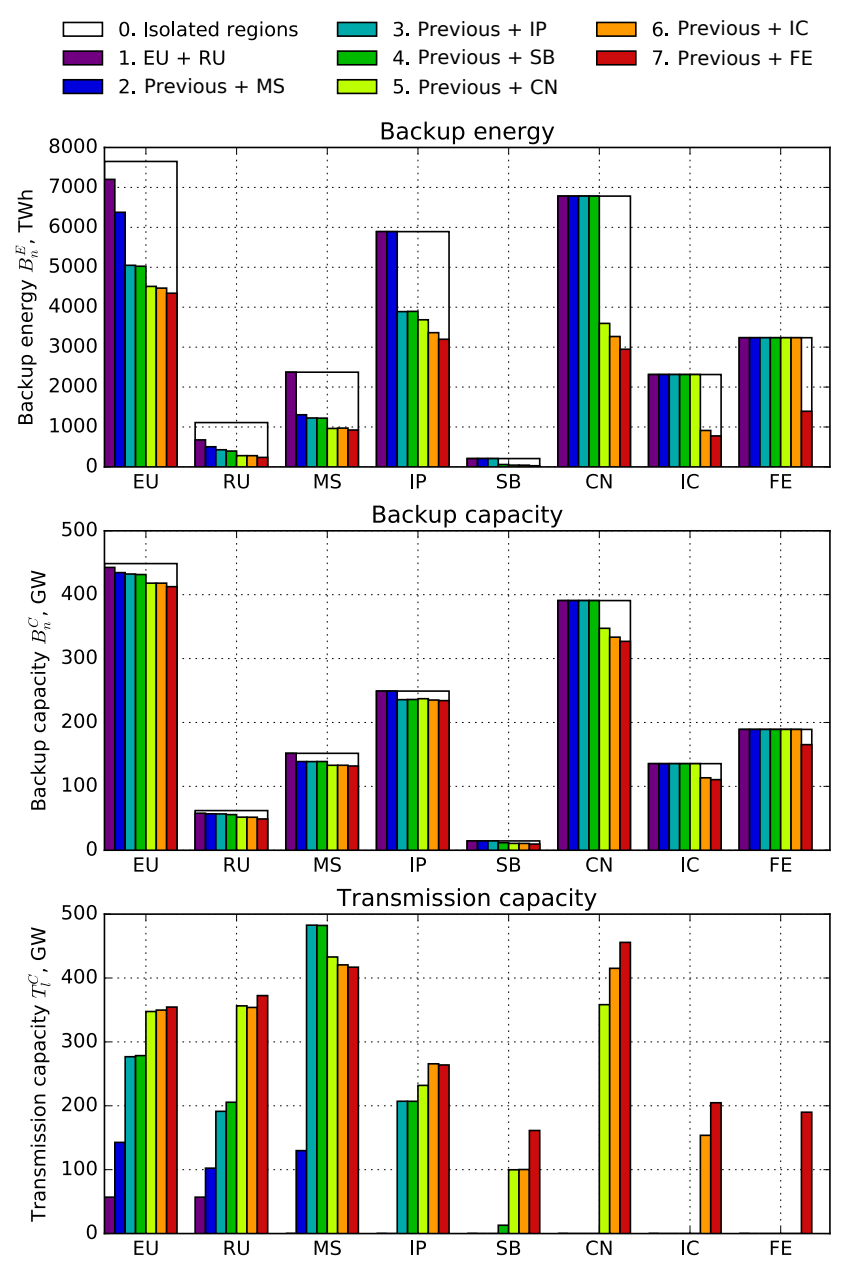

Figure 7. Need for backup energy, backup capacity and transmission capacity of the Eurasian regions in dependency of the grid expansion from west to east, $\alpha=1$. The node labels are listed in the order of connection to a grid.

found by other studies. (Dahl et al., 2017) found the need for backup energy decrease from 18 to $10 \%$ of the total consumption if Europe, Russia, North-Africa and the Middle East are connected.

Besides, the importance of using multiple weather years to obtain reliable results in the modelling of renewable energy systems was substantiated by the observed yearly variation within the 10-year period.

It can be concluded that a pan-continental Eurasian power grid has the potential to reduce fluctuations on the generation side and consequently the need for dispatchable backup power to a large degree.

Data availability. Data on generation and load per node is publicly available (Krutova et al., 2017). The only exception is the load time series for the EU node, which was produced within the project 
RESTORE 2050. The copyright for this data is owned by the Wuppertal Institute.

Competing interests. The authors declare that they have no conflict of interest.

Special issue statement. This article is part of the special issue "16th EMS Annual Meeting \& 11th European Conference on Applied Climatology (ECAC)". It is a result of the 16th EMS Annual Meeting \& 11th European Conference on Applied Climatology (ECAC), Trieste, Italy, 12-16 September 2016.

Acknowledgements. The work is part of the RESTORE 2050 project (Wuppertal Institute, Next Energy, University of Oldenburg) that is financed by the Federal Ministry of Education and Research (BMBF, Fkz. 03SFF0439A, 2013-2016). We would like to thank our project partners from Wuppertal Institute and Next Energy for helpful discussions. We thank two reviewers for helpful comments and suggestions, which helped to improve this manuscript.

Edited by: Sven-Erik Gryning

Reviewed by: Guido Plessmann and one anonymous referee

\section{References}

Bogdanov, D. and Breyer, C.: Eurasian Super Grid for 100\% Renewable Energy power supply: Generation and storage technologies in the cost optimal mix. In ISES Solar World Congress, 812, 2015.

Brown, T.: Transmission network loading in Europe with high shares of renewables, IET Renewable Power Generation, 9, 5765, 2014.

Brown, T., Schlachtberger, D., Kies, A., and Greiner, M.: Sector Coupling in a Highly Renewable European Energy System, in: 15th Wind Integration Workshop, 2017.

Chattopadhyay, K., Kies, A., Lorenz, E., von Bremen, L., and Heinemann, D.: The impact of different PV module configurations on storage and additional balancing needs for a fully renewable European power system, Renewable Energy, 113, 176-189, 2017.

Chatzivasileiadis, S., Ernst, D., and Andersson, G.: The global grid, Renewable Energy, 57, 372-383, 2013.

Chatzivasileiadis, S., Ernst, D., and Andersson, G.: Global power grids for harnessing world renewable energy. Renewable Energy Integration: Practical Management of Variability, Uncertainty and Flexibility in Power Grids, 175-188, 2014.

Dahl, M., Rodriguez, R. A., Søndergaard, A. A., Zeyer, T., and Andresen, G. B.: Infrastructure Estimates for a Highly Renewable Global Electricity Grid, in: New Horizons in Fundamental Physics, 333-356, Springer International Publishing, 2017.

Francois, B., Borga, M., Creutin, J. D., Hingray, B., Raynaud, D., and Sauterleute, J. F.: Complementarity between solar and hydro power: sensitivity study to climate characteristics in NorthernItaly, Renewable Energy, 86, 543-553, 2016.
Heide, D., Von Bremen, L., Greiner, M., Hoffmann, C., Speckmann, M., and Bofinger, S.: Seasonal optimal mix of wind and solar power in a future, highly renewable Europe, Renewable Energy, 35, 2483-2489, 2010.

Heide, D., Greiner, M., Von Bremen, L., and Hoffmann, C.: Reduced storage and balancing needs in a fully renewable European power system with excess wind and solar power generation, Renewable Energy, 36, 2515-2523, 2011.

Hirth, L. and Müller, S.: System-friendly wind power: How advanced wind turbine design can increase the economic value of electricity generated through wind power, Energy Economics, 56, 51-63, 2016.

Jurasz, J. and Ciapała, B.: Integrating photovoltaics into energy systems by using a run-off-river power plant with pondage to smooth energy exchange with the power gird, Applied Energy, 198, 2135, 2017.

Kies, A., Nag, K., Bremen, L. V., Lorenz, E., and Heinemann, D.: Investigation of balancing effects in long term renewable energy feed-in with respect to the transmission grid. Advances in Science and Research, 12, 91-95, 2015.

Kies, A., Schyska, B. U., and von Bremen, L.: Curtailment in a highly renewable power system and its effect on capacity factors, Energies, 9, 510, 2016a.

Kies, A., Chattopadhyay, K., von Bremen, L., Lorenz, E., and Heinemann, D.: Simulation of renewable feed-in for power system studies, RESTORE 2050 project report, 2016b.

Kies, A., Schyska, B. U., and von Bremen, L.: The Demand Side Management Potential to Balance a Highly Renewable European Power System, Energies, 9, 955, 2016 c.

Kies, A., Schyska, B. U., and von Bremen, L.: The optimal share of wave power in a highly renewable power system on the Iberian Peninsula, Energy Reports, 2, 221-228, 2016 d.

Krutova, M., Kies, A., Schyska, B., and von Bremen, L.: Load and renewable generation time series for selected regions in Africa and Eurasia, https://doi.org/10.5281/zenodo.825759, 2017.

Lund, H.: Large-scale integration of optimal combinations of PV, wind and wave power into the electricity supply, Renewable energy, 31, 503-515, 2006.

Lund, H.: Large-scale integration of wind power into different energy systems, Energy, 30, 2402-2412, 2008.

Pleßmann, G., Erdmann, M., Hlusiak, M., and Breyer, C.: Global energy storage demand for a $100 \%$ renewable electricity supply, Energy Procedia, 46, 22-31, 2014.

Rienecker, M. M., Suarez, M. J., Gelaro, R., Todling, R., Bacmeister, J., Liu, E., and Bloom, S.: MERRA: NASA's modern-era retrospective analysis for research and applications, J. Climate, 24, 3624-3648, 2011.

Santos-Alamillos, F. J., Pozo-Vázquez, D., Ruiz-Arias, J. A., LaraFanego, V., and Tovar-Pescador, J.: Analysis of spatiotemporal balancing between wind and solar energy resources in the southern Iberian Peninsula, J. Appl. Meteorol. Climatol., 51, 20052024, 2012.

Strbac, G.: Demand side management: Benefits and challenges, Energy policy, 36, 4419-4426, 2008.

Tafarte, P., Das, S., Eichhorn, M., and Thrän, D.: Small adaptations, big impacts: Options for an optimized mix of variable renewable energy sources, Energy, 72, 80-92, 2014. 
Vidal-Amaro, J. J., Østergaard, P. A., and Sheinbaum-Pardo, C.: Optimal energy mix for transitioning from fossil fuels to renewable energy sources - The case of the Mexican electricity system, Appl. Energ., 150, 80-96, 2015.

Ward, K.: The world in 2050, From the top, 30, 2012.

Weitemeyer, S., Kleinhans, D., Wienholt, L., Vogt, T., and Agert, C.: A European perspective: potential of grid and storage for balancing renewable power systems, Energy Technology, 4, 114-122, 2016.

Wang, Y.: Global Energy Interconnection, The International Conference on Electrical Engineering, Hong Kong, 5-9 July 2015. 